\title{
Erythema Measurement
}

National Cancer Institute

\section{Source}

National Cancer Institute. Erythema Measurement. NCI Thesaurus. Code C116568.

The use of instruments to quantify the redness of the skin. This is done to measure differences in erythema over time in a single patient and to gauge the stability or progression of a skin disease. 